\title{
Phase-chronometric measuring systems for the provision of technological processes and diagnostics of the production of electromechanical engineering systems
}

\author{
Ekaterina Tumakova ${ }^{1, *}$, and Aleksandr Komshin ${ }^{1}$ \\ ${ }^{1}$ Bauman MSTU, Machine building technology Department, 105005 Moscow, Russia
}

\begin{abstract}
In paper the main problems and objectives assessment of the current technical condition of the machine-building equipment are considered. Modern measuring systems used in engineering analysis. The paper considers a phase-chronometric information technology-metrological support for the evaluation of the technical condition of the synchronous electromechanical systems on the example of turbine CHP. Analysis of the main problems in the diagnosis of electromechanical systems is given. Phase-chronometric method as a basis for building a new system of diagnosis of electromechanical systems reviewed. The paper describes the main elements of technology, assessment of the economic effects of its introduction in the industry.
\end{abstract}

The quality of repair of the main and auxiliary equipment at the majority of thermal power plants (TPPs) and combined heat and power plants (CHP plants) has significantly deteriorated over the past few years. Qualification of specialists in the field of diagnostics of these objects continues to fall every year. At the same time, it is difficult to estimate the damages caused by the failure of the turbine due to an accident. In addition to the economic losses that arise in the enterprise itself, which generates electricity, significant losses are borne by enterprises and organizations that have not received this energy. In addition, it is necessary to take into account the repair costs for the restoration of equipment that has suffered an accident, depending on its scale.

An accident or failure of the main or auxiliary equipment of a TPP or CHP plant can lead to significant losses, and in some cases, catastrophic consequences in a number of ways:

- Underdevelopment of planned energy by a particular power plant can lead to losses associated with higher energy costs due to the connection of energy sources with lower efficiency.

- The exclusion of a part of the power plant's equipment leads to a rise in the cost of electricity production due to a decrease in the equipment utilization rate.

- Repair costs for restoring equipment that has been damaged (depends on the scale of the accident).

- Damage to enterprises that have not received energy, as a result of an accident or a lack of the necessary capacity reserve for power generating stations.

- Damage to the population caused by a sudden stoppage of public electric transport, interruptions in mass events, disconnection of household appliances, etc.
Serious consequences for long breaks in the heat supply of houses and businesses. [1]

At present, a number of diagnostic methods are known for technical diagnostics of turbine units, the purposes of which are: monitoring of technical condition, finding a location and determining the causes of failures (failures) and forecasting technical condition. The most widely used diagnostic methods based on vibration (vibration spectrum analysis, high-frequency vibration - "shock pulse method", vibration estimation, vibration velocity, vibration acceleration, etc.). [2]

To effectively solve the problems of creating and operating turbine units of a CHP, it is necessary to use methods and diagnostic tools that have a single principle of presenting metrological and information support for the investigated object at all stages of the life cycle. This possibility is provided by the phase-chronometric method, developed at the Bauman MSTU. [3, 4]

As an important feature of the phase-chronometric method, it should be noted that it belongs to the phase measurement methods. [5] When studying the devices of cyclic action, the operation of the phase-chronometric system is based on recording the moment of passage of a certain value of the phase of the cycle. Information on the technical state of the object is contained in variations in the duration of time intervals corresponding to the passage of the intervals (quanta) of the phase.

The use of the phase-chronometric method opens up new possibilities. Phase-chronometric diagnostic systems have a higher metrological level: the phase study provides fundamentally new information, and chronometry makes it possible to improve accuracy.

Accuracy, speed and completeness of the obtained characteristics of the turbine unit in combination with mathematical models provide both control of the

\footnotetext{
* Corresponding author: tumakova_ekaterina91@mail.ru
} 
development of emergency situations and control of the residual resource.

In order to create an effective diagnostic system, it is necessary to perform computational mathematical modeling along with measuring the controlled parameters in order to identify the object under study with its operating modes. Including simulating critical defects and emergency operating modes, this cannot be realized experimentally. [6]

In this work, a mathematical model was developed that should ensure the connection between theory and practice. The input and output parameters of the mathematical model have the same format as the measurement data. The parameters studied during the experiment are physical-mechanical and structuraltechnological parameters of the object.

The model performs a diagnostic role, namely, defects or deviations from the norm are laid in it, and the response to them of the system is analyzed. As a result, defect detection algorithms are formed in real experimental data obtained by the time interval measurement system. [7]

To construct a mathematical model of a functioning electromechanical system, the maximum possible approximation of the equations to be modeled in a model to a specific object is necessary. The model includes equations (blocks of programs) describing the individual elements of the investigated object (excitation, control system, etc.). For the elements of the object that require special attention (the place of the most frequent breakdowns), the model moves from their general description to the particular one. [8]

\section{Measurement and control of torsional oscillations of shafting}

Opportunities are opened to address current day-to-day tasks of operating heat and power engineering, such as:

- prevention of damage to rotors of steam turbines;

- diagnostics of crack formation in rotors of turbines and generators under operating conditions;

- measurement and control of torsional oscillations of shaft lines for the purpose of recording accumulated damage;

- creation and introduction of stationary and portable monitoring systems for torsional oscillations of shafts of turbine units, etc.

An example of the chronogram of the turbine unit turbine rotation and the natural frequency spectrum of the torsional oscillations of the turbo unit are shown in Figures 1 - 4. [9]

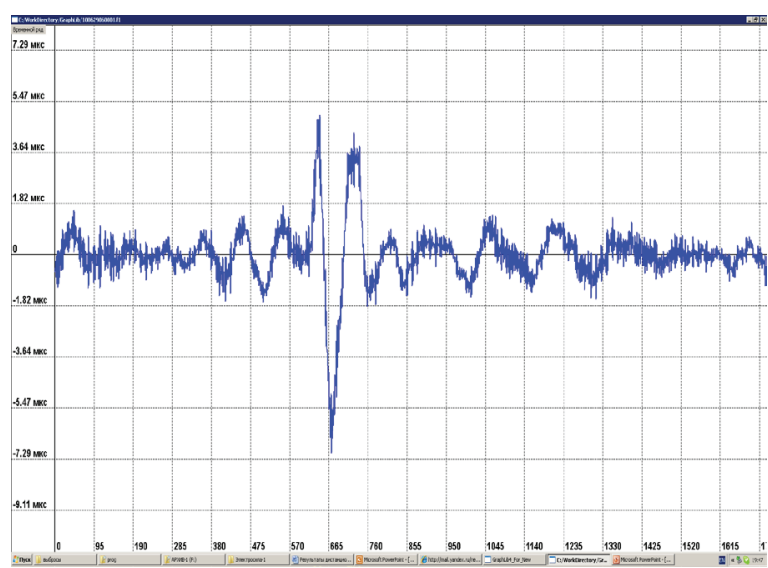

Fig. 1. Chronogram of rotation of turbo unit TVB-200-2-K200-130.

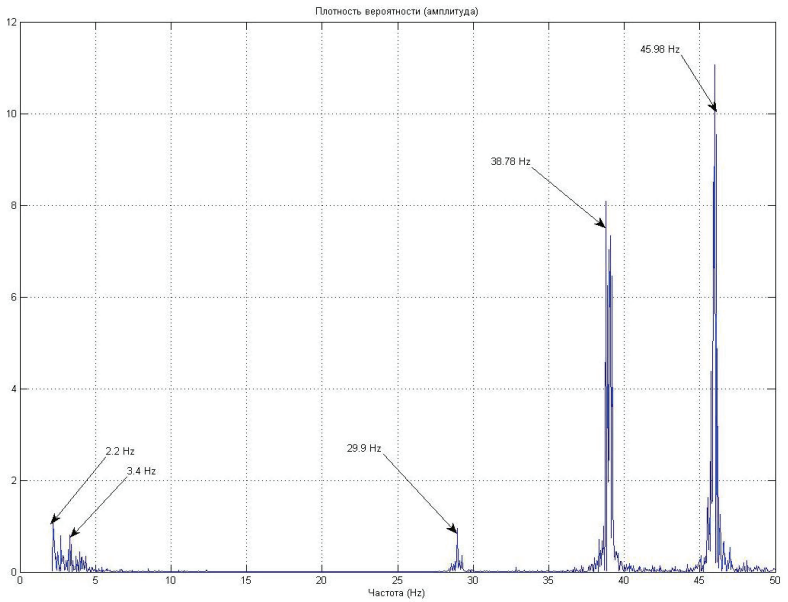

Fig. 2. Spectrum of natural frequencies of torsional vibrations of turbine TIA-220-2-K-200-130.

Here the following main frequencies are distinguished: $2,2 \mathrm{~Hz}, 3,4 \mathrm{~Hz}, 28,9 \mathrm{~Hz} 38,78 \mathrm{~Hz}$ and $45,98 \mathrm{~Hz}$.

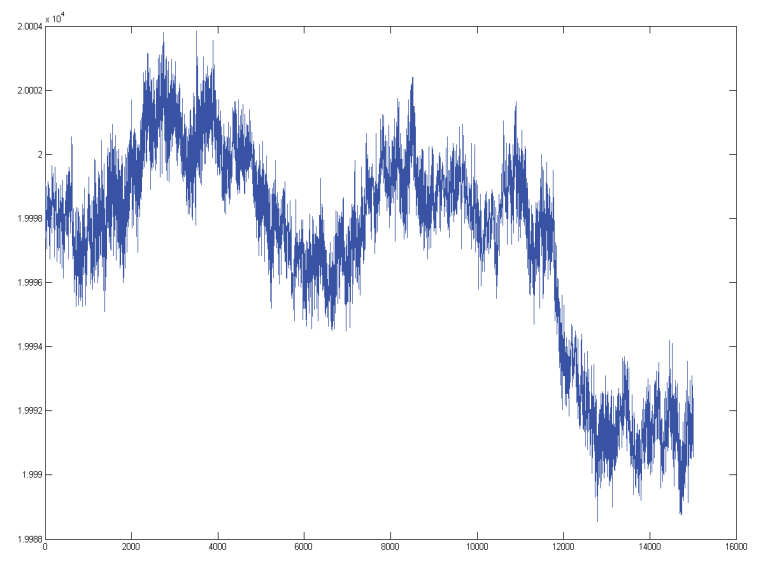

Fig. 3. Chronogram of rotation of turbo unit TVB-320-2UZ-T$250 / 300-240-2$. 


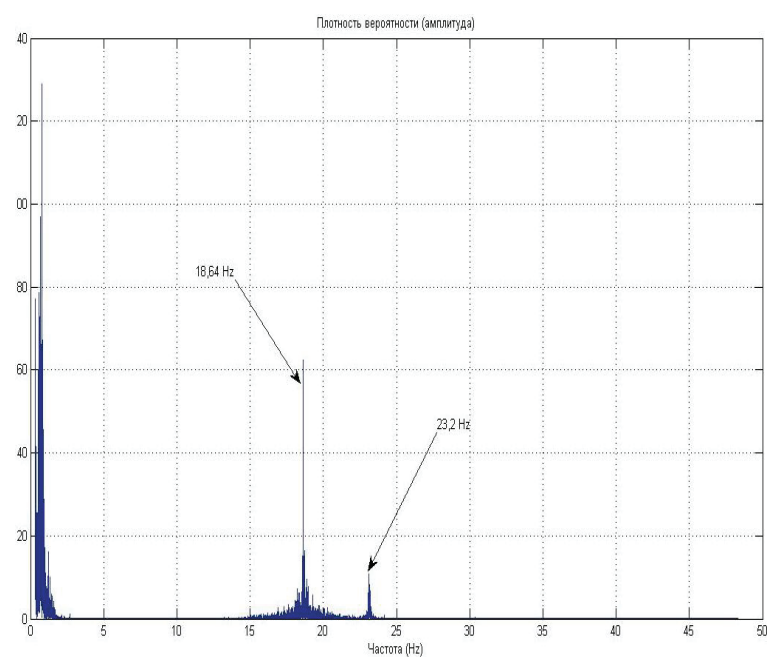

Fig. 4. Spectrum of natural frequencies of torsional vibrations of turbine TVB-320-2UZ-T-250 / 300-240-2.

Here the following main frequencies are distinguished: $18,64 \mathrm{~Hz}$ и $23,2 \mathrm{~Hz}$.

\section{Diagnostics of elements of electromechanical systems during operation}

In the process of operation one of the key challenges is the diagnosis of technical condition of functioning of the object.

Consider the example of the detection and localization of a malfunction of the turbogenerator. In Fig. 5 shows the chronogram of rotation of the defective turbo generator TVV-320-2У3-T-250/300-240-2 where in the process (without stop machine) discovered the sparking brushes of the brush unit.

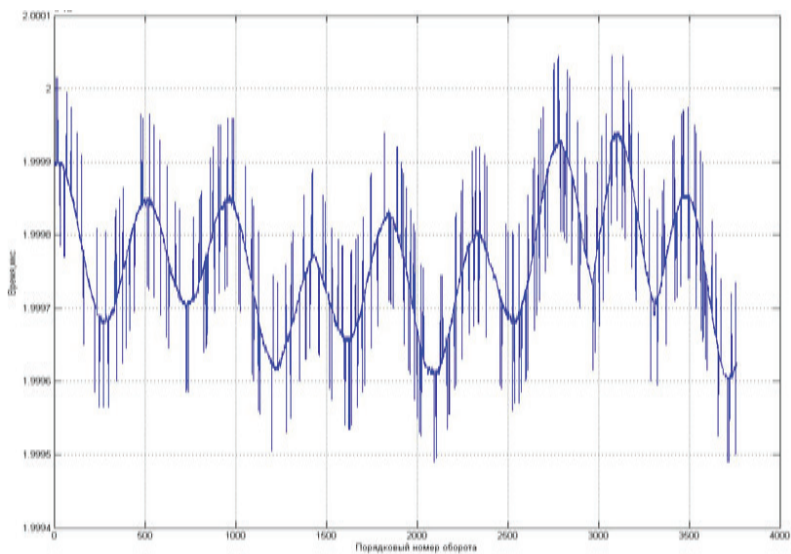

Fig. 5. The chronogram of rotation of the turbo generator TVV-320-2У3-T-250/300-240-2 reflecting the diagnosed defect - sparking brushes of the brush unit.

This defect is manifested as follows: observed periodic bursts of high amplitude on the chronograms of rotation of the turbine. The reason for the fault can be [10]:

- unbalance of brushes or their incorrect installation;

- weak contact of brushes to the collector;
- poor contact in the pick-up rings;

- irregular arrangement of the main and additional poles.

Thus, in the process of operation is determined by the defect is localized in the design of the entire turbine unit, is determined by the cause of the malfunction, i.e. solved a direct problem diagnostic: monitoring of the technical state of the object, evaluation of technical condition and forecasting of a residual resource of elements or turbine unit as a whole. [9]

\section{Economic efficiency of the introduction of phase-chronometric systems in heat power engineering}

To estimate the magnitude of the economic effect and the appropriateness of introducing the phasechronometric method in power engineering, calculations were made based on the following initial data for thermal power plants:

- The cost of installing a new TA (T-250-300) at the station is 1500 million rubles. This number is obtained on the basis of averaging of open tender information, since there is no standard cost, and the specific cost is specified depending on the features of the station and the operating conditions of the repair organization.

- The service life of the turbine unit can be extended to 50 years, there are data on the appointment of an individual resource to turbines for such a period by the decision of technical experts, although there have been cases of turbines and longer periods.

- The project lifetime is 50 years.

- For the normal level of project costs (100\%), the value obtained during operation of the turbine set by the standard is accepted, where the service life is 25 years, and the repair interval is 4 years. During the project, 2 turbo units are required - at the beginning of operation and after 25 years.

- When extending the service life of the turbine unit, a period of 50 years is assigned - 1 turbine unit is required throughout the project.

- Carrying out of major repairs (MR) it is estimated in 32 million roubles.

- Average repair (AR) is estimated at 7 million roubles.

- Carrying out of the current repair (CR) is estimated at 4 million roubles.

The economic effect of the introduction of information-metrological phase-chronometric technology is calculated. In the end, if the effect of extending the resource will be reached by half, that is, in the amount of 15 million roubles. For one unit, the result of the project in the projected prices (discounted at a rate of $11 \%$ ) will be as follows:

- net reduced income - 970 million roubles.

- Payback period - 4 years.

Economic calculations were carried out jointly with the department of IBM "Industrial logistics" MSTU.

The result shows, that the project has a good reserve on size of received economy at prolongation of a resource of a turbo generator. [9] 
Diagnosis of the technical state of electromechanical systems is relevant for various areas of modern industry, such as nuclear power, oil and gas transmission, heat supply, water supply, etc. [8]

The development of electromechanical systems and their diagnostics is an integral part of the modern world. Recently, the use of low-power electric cars has increased significantly - in automation and computer equipment. The development and creation of new types of generators is becoming increasingly important every year. So, since 2012 in the United States, work is under way to create a new type of deep-water electric generator that can transform into electricity the energy of stable deep currents - a source of clean energy. [11]

This work was supported as part of the research 9.4968.2017/BP for the implementation of the initiative scientific projects basic part of state task.

\section{References}

1. A.D. Trukhniy, B.V. Lomakin, Thermal steam turbines and turbine units: a textbook for high schools (MEU, 2002)

2. O.S. Vakhromeev, R.T. Karimov, A.I. Nadeev, Modern methods of diagnostics of electromechanical systems (2005)

3. Zroychikov [and others], Heat Power Engineer. 6 (2005)

4. M.I. Kiselev [and others], Heat Power Engineer. 11 (2006)

5. A.B. Syritskii, Meas. Techn. 6 (2016)

6. K.S. Ermakov, E.V. Tumakova, Sciencee.\& Educ. 10 (2015)

7. D.D. Boldasov, K.G. Potapov, A.B. Syritskii, Russ. Eng. Research 8 (2016)

8. E.V. Tumakova, Meas. Techn. 6 (2016)

9. E.V. Tumakova, A.S. Komshin, IIKYSS (2014)

10. A.S. Komshin, O.V. Medvedeva, Meas. Techn. 5 (2014)

11. E.V. Tumakova, A.S. Komshin, The Fut. Eng. Of Russ. (2015) 